\title{
Exploring e-mobile banking implementation barriers on Indonesian millennial generation con- sumers
}

\author{
Elimawaty Rombe $^{a^{*}}$, Zakiyah Zahara ${ }^{a}$, Ira Nuriya Santi ${ }^{a}$ and Marjam Desma Rahadhini ${ }^{\mathrm{b}}$
}

${ }^{\mathrm{a}}$ Economic and Business Faculty, Tadulako University, Palu, Central Sulawesi, Indonesia ${ }^{b}$ Economic Faculty, University of Slamet Riyadi Surakarta, Indonesia

\section{H R O N I C L E}

Article history:

Received: June 8, 2021

Received in revised format: June

30,2021

Accepted: August 22, 2021

Available online: August 23, 2021

Keywords:

e-Mobile Banking

Millennial Generation Consumers

Banking

\section{A B S T R A C T}

The purpose of this study was to determine the effect of value barriers, risk barriers, image barriers, cost barriers and usage barriers on the use of mobile banking in millennial generation customers. This research used a quantitative approach and the sampling technique used is purposive sampling which conducts research on a group of subjects with certain characteristics or is considered closely related to previously known population characteristics. This research was conducted by distributing 140 online questionnaires to mobile banking users and there were 110 questionnaires that were reversed and processed. Sampling methods use snowball sampling. The results indicate that there was a positive but not significant effect between risk barriers and mobile banking adoption intentions. However, there was a negative influence between image barriers and mobile banking adoption intentions. Moreover, there was a positive influence between perceived cost barriers and mobile banking adoption intentions, there was a positive influence between the barriers to use and mobile banking adoption the intention to adopt. Finally, there was a significant influence between value barriers and mobile banking adoption intentions.

\section{Introduction}

In the digital era, all human conveniences are present in every line of life through technological developments. This can be seen from the development of digital-based information and communication technology, which means that information can be managed in real-time without human assistance by using an automated and sophisticated system. According to Agwu et al. (2014) and Anus et al. (2011), information can be obtained through gadgets in the form of smartphones or laptops that are integrated through the internet. With this convenience, it will increase the level of adoption of digital-based information and communication technology in the community. According to Hongxia et al. (2011), humans continue to compete in creating information technology that is sophisticated, safe, and provides accurate and real-time information. As a result, several sectors have changed with the development and innovation of these technologies, including the banking sector. According to Anus et al. (2011), banks compete in providing services through information and communication technology so that they can position themselves as banks that have more value than their competitors. With the development of information technology, it is possible for banks to provide services that are tailored to the needs of customers who have developed in line with technological developments and lifestyles. According to Ali and Kamran (2017), Albadvi and Gharaee (2009), through mobile banking services, customers can access services provided by banks such as account management, requesting information, transferring funds, or paying bills. By using mobile banking services, customers can perform banking transactions anywhere and anytime.

* Corresponding author.

E-mail address: elimawatyrombe@untad.ac.id (E. Rombe) 
Customers no longer need to come to the bank or ATM to just check balances or transfer funds. Despite the benefits of using mobile banking services, acceptance or adoption of mobile banking services is still low. The low acceptance of mobile banking services is due to resistance from customers. According to Hanafizadeh et al. (2014), Hongxia et al. (2011), resistance to mobile banking services causes mobile banking services to be less well known. Resistance causes the use of mobile banking services to run slowly and not as expected. Therefore, resistance needs to be understood and controlled. According to Ali and Kamran (2017), an understanding of resistance and the factors that cause resistance is very necessary, to be more efficient in efforts to improve and identify competitiveness and productivity. This can later be used as evaluation material and provide insight into customer mindsets, so that banks can develop appropriate strategies to reduce resistance and improve mobile banking services. Bao et al. (2012) define mobile banking services as a term used for banking transactions using mobile devices such as mobile phones or smartphones. According to Bamoriya et al. (2012) mobile banking services are internet banking using mobile devices, known as m-banking or SMS banking. According to Brahim et al. (2015), Hanafizadeh et al. (2014), Hongxia et al. (2011) mobile banking service is a banking service that uses mobile equipment with Wireless Application Protocol (WAP) or without using WAP. While internet banking is a banking transaction service that is carried out using a set of computers or laptops using the internet network. However, it is currently possible to access internet banking services using mobile devices. According to Behl (2016) and Bamoriya et al. (2012), the disadvantage of internet banking services is that they must always be connected to the internet network, to carry out banking transactions. Mobile banking services were first introduced in early 2000 using Sort Messaging Service (SMS) and Wireless Application Protocol (WAP) or General Packet Radio Service (GPRS). In contrast to using SMS, which is considered cheaper and faster to use in banking transactions. According to Brahim et al. (2015) using SMS and WAP, banks also offer mobile banking services. Barriers to M-Banking adoption are important information for banks in determining the right steps so that M-Banking can be accepted by millennials. The results of this study help banks have better insight into the relationship between all barriers and consumer adoption intentions of M-Banking on bank services.

\subsection{Image Barriers}

Image barriers are the individual's negative thoughts about technological tools and perceptions of complications of use. According to Bao et al. (2012), Bharti (2016), Behl (2016), Bamoriya et al. (2012), the image barrier is formed if consumers have negative expectations of the brand, industry, country, and the effects of the innovation. Image barriers are uniquely formed through prejudice or clichés, therefore the assessment is considered subjectively each.

\section{$\mathbf{H}_{1}$ : Image barriers have a negative effect on adoption intentions.}

\subsection{Cost Perception Barriers}

Cost perception is the extent to which consumers expect that using a particular technology will cost money. According to Bao et al. (2012), Bharti (2016), Behl (2016), Bamoriya et al. (2012), this barrier is influenced by the costs felt by users in using innovative products.

\section{$\mathbf{H}_{2}$ : Perceived cost barriers have a negative effect on adoption intentions.}

\subsection{Risk Barriers}

According to Brahim et al. (2015), Hanafizadeh et al. (2014), Hongxia et al. (2011), barriers to risk are closely related to the risks that can be accepted by users in using products or services that they do not know about. With the changes that innovation brings to consumers, also certain risks are associated with them because a new product or service contains some uncertainties. Consumers who are aware of risk tend to resist innovation.

\section{H3: Risk barriers have a negative effect on adoption intentions.}

\subsection{Usage Barriers}

According to Mei Ngan (2017), Okpara et al. (2014), Sarokolaei et al. (2012) and Siano et al. (2020), usage barriers come into play when innovations are incompatible with existing workflows, practices or habits, and these are perhaps the most common cause of consumer resistance to innovation. Another factor that can affect user barriers is the complexity of using the innovation product. Complexity is the degree to which an innovation is perceived as difficult to understand and use. This factor indicates that the adoption rate of innovative products will be high if consumers feel the ease of use of the products offered by innovative products.

\section{$\mathbf{H}_{4}$ : Barriers to use have a negative effect on adoption intentions.}

\subsection{Value Barrier}

Value barriers address the value that innovation provides to consumers. More specifically, it refers to the monetary value of innovation and that innovation needs to deliver a convincing "performance value - best price". According to Joshi et al. 
(2013), Laukkanen et al. (2008) and Moorthy et al. (2017), value barriers are resistance to the use of products or services when they do not meet the user's perception of the value of performance to price in contrast to other substitutes. The rejection of the use of this product is due to user dissatisfaction and the manufacturer's inability to meet user perceptions of using the product.

\section{$\mathrm{H}_{5}$ : Value barriers have a negative effect on adoption intentions.}

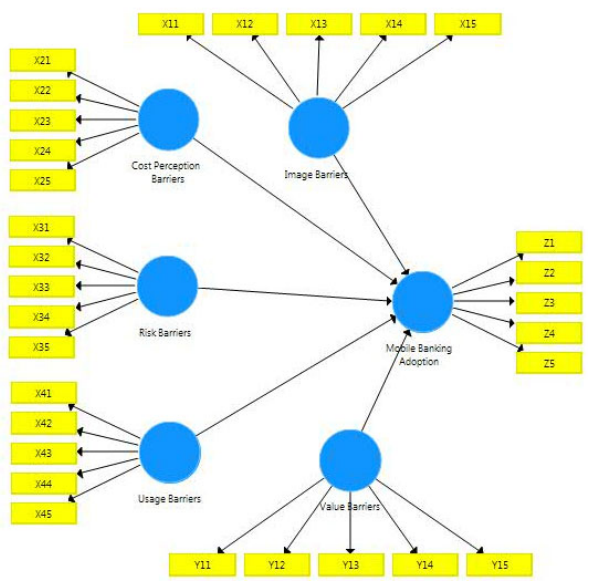

Fig 1. Research Model

\section{Method}

Researchers used a quantitative approach in this study. The sampling technique used is purposive sampling which conducts research on a group of subjects with certain characteristics or is considered closely related to previously known population characteristics. This research was conducted by distributing 140 online questionnaires to mobile banking users and there were 110 questionnaires that were reversed and processed. Sampling method with snowball sampling. Statistical testing in this study was carried out with the help of the Statistical Structural Equation Modeling (SEM) tool based on Partial Least Square version 3. The validity test was used to measure the validity of the inductor items in a questionnaire. The validity test in this study uses convergent validity by looking at the minimum value of the factor loading indicator for each indicator item 0.6 (Purwanto, 2021). The next reliability test is by looking at the Cronbach's Alpha value and the Composite Reliability value used to measure internal consistency in the data reliability test, as well as the AVE (Average Variance Extracted) value as the average percentage of variance scores extracted from a set of latent variables estimated through loading standardize. For this test, the researcher will also use the limits of Composite Reliability $>0.7$ and Cronbach's Alpha $>0.6$ (Purwanto, 2020), and AVE value $>0.5$.

\subsection{Validity test and Hypothesis testing}

With the aim of knowing the validity or invalidity of the statement use in the questionnaire, the statement is declared valid if the statement used indicates something that will be measured (Latan, \& Noonan, 2017). Validity testing focuses on all variables that have a unidimensional form. For this study, using convergent validity testing, namely through the Average variance extracted (AVE) value for each (Latan, \& Noonan, 2017). Validity of an indicator if the AVE value is equal to or more than 0.5 According to Hair et al. (2019) after a research model is believed to be fit, a hypothesis test can be carried out. The next step is to test the hypothesis that has been built in this study. Hypothesis testing using the Bootstrapping function on SmartPLS 3.0. The hypothesis is accepted when the significance level is less than 0.05 or the $t$-value exceeds the critical value (Hair et al., 2014). The value of $t$ statistics for the $5 \%$ significance level is 1.96 .

\section{Result and Discussion}

\subsection{Reliability test}

According to Hair et al. (2019), reliability is a measure of the internal consistency of indicators of a construct that shows the degree to which each of these indicators shows a general latent construct. According to Hair et al. (2019) the reliability requirement is a measure of the stability and consistency of the results at different times. To test the reliability of the construct in this study used the value of composite reliability. A variable is said to meet construct reliability if it has a composite reliability value $>0.7$ (Purwanto et al., 2019) and the alpha Cronbach value $>0.7$ has a good level of reliability for a variable. In Table 1, it can be seen the results of the reliability test analysis using the SmartPLS tool which states that all composite reliability values are greater than 0.7 , which means that all variables are reliable and have met the test criteria. Furthermore, 
the value of Cronbach's omission also shows that all Cronbach's alpha values are more than 0.6 and this indicates the level of reliability of the variable has also met the criteria.

Table 1

Reliability Testing Result

\begin{tabular}{|c|c|c|c|c|}
\hline & Cronbach's Alpha & rho_A & Composite Reliability & $(\mathrm{AVE})$ \\
\hline Cost Barriers & 0.995 & 1.025 & 0.996 & 0.986 \\
\hline Image Barriers & 0.982 & 0.983 & 0.988 & 0.966 \\
\hline Mobile Adoption & 0.91 & 0.941 & 0.935 & 0.782 \\
\hline Risk Barriers & 0.974 & 1.096 & 0.982 & 0.948 \\
\hline Usage Barriers & 0.984 & 1.032 & 0.992 & 0.984 \\
\hline Value Barriers & 0.98 & 1.081 & 0.99 & 0.98 \\
\hline
\end{tabular}

\subsection{Convergent Validity}

Convergent validity is used to measure the correlation between item scores and construct scores, the higher the correlation the better the data validity (Purwanto et al., 2020). Measurement can be categorized as having convergent validity if the loading factor value is $>0.7$.

\subsection{Discriminant Validity}

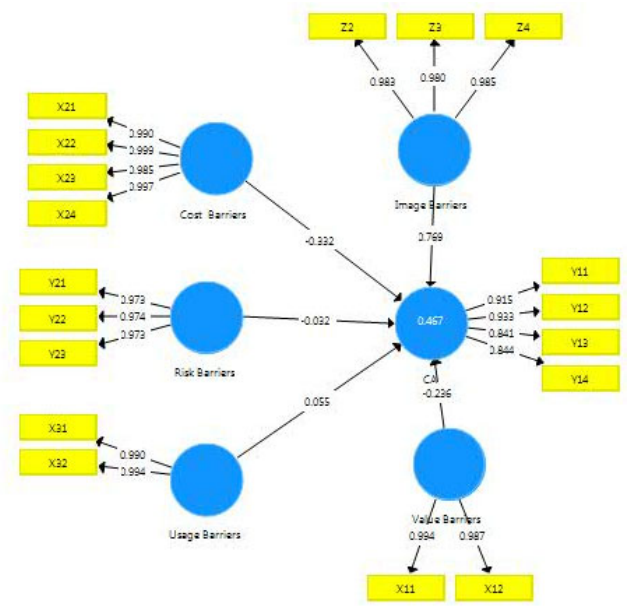

Fig. 2. Validity Testing

Discriminant validity is a test of construct validity by predicting the size of the indicator from each block (Hair, 2019). One of the discriminant validities can be seen by comparing the AVE value with the correlation between other constructs in the model. If the AVE root value is $>0.50$, it means that discriminant validity is reached (Hair, 2018). Discriminant validity was also carried out based on the Fornell Larcker Criterion measurement with the construct. If the correlation of the constructs on each indicator is greater than the other constructs, it means that latent constructs can predict indicators better than other constructs (Purwanto et al., 2020).

Table 2

Discriminant validity Result

\begin{tabular}{|c|c|c|c|c|c|c|}
\hline & Cost Barriers & Image Barriers & Mobile Adoption & Risk Barriers & Usage Barriers & Value Barriers \\
\hline Cost Barriers & 0.993 & & & & & \\
\hline Image Barriers & 0.307 & 0.983 & & & & \\
\hline Mobile Adoption & -0.13 & 0.576 & 0.884 & & & \\
\hline Risk Barriers & -0.142 & -0.062 & -0.04 & 0.973 & & \\
\hline Usage Barriers & 0.29 & 0.597 & 0.237 & -0.215 & 0.992 & \\
\hline Value Barriers & 0.233 & 0.533 & 0.141 & -0.017 & 0.795 & 0.99 \\
\hline
\end{tabular}

Based on Table 2, it appears that each statement indicator has the highest loading factor value in the tested latent constructs than other latent constructs, meaning that each statement indicator can be predicted well by each latent construct in other words discriminant validity is valid.

\subsection{R Square Value}

The value of R square (R2) is a measure of the proportion of the variation in the value of the affected variable which can be explained by the variable that influences it. If in a study using more than two independent variables, then the adjusted r-square 
(adjusted R2) is used. The value of r square adjusted is a value that is always smaller than $\mathrm{r}$ square. The R2 value is close to 1 , with the limiting criteria being divided into 3 classifications, If the value of $\mathrm{R}^{2}=0.67$ Model is substance (strong), If the value of $\mathrm{R} 2=0.33$ the model is moderate (medium) and If the value of $\mathrm{R}^{2}=0.19$ the model is weak (bad)

Table 3

$\underline{\text { R Square Value }}$

\begin{tabular}{ccc}
\hline & R Square & R Square Adjusted \\
\hline Mobile Adoption & 0.467 & 0.457 \\
\hline
\end{tabular}

Based on Table 3, the R Square of Mobile Adoption value is 0.457 or $45.7 \%$ means that the Mobile Adoption variable is influenced by value barriers, risk barriers, image barriers, cost barriers and barriers to the use of t variable by $45.7 \%$, while the remaining $54.3 \%$ is influenced by other variables not discussed in this study.

\subsection{Hypothesis testing}

According to Hair et al. (2019) after a research model is believed to be fit, a hypothesis test can be carried out. The next step is to test the hypothesis that has been built in this study. In this case, the bootstrapping method is applied to the sample. Testing with bootstrapping is intended to minimize the problem of abnormal research data.

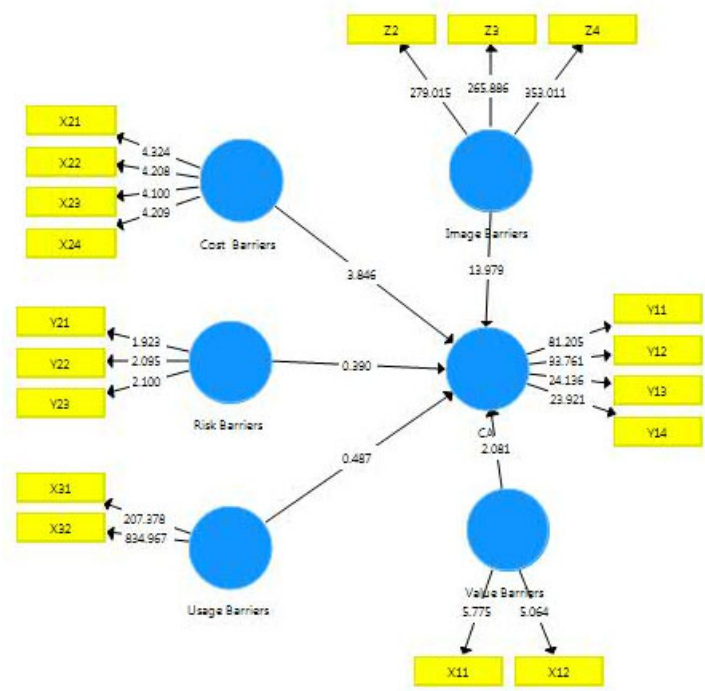

Fig. 3. Hypothesis Testing

The last step of the test using the Smart Pls application is hypothesis testing and is carried out by looking at the results of the bootstrapping value. Hypothesis testing using the Bootstrapping function on SmartPLS 3.0. The hypothesis is accepted when the significance level is less than 0.05 or the $t$-value exceeds the critical value (Hair et al, 2014). The value of $t$ statistics for the $5 \%$ significance level is 1.96 .

Table 4

Hypothesis Testing

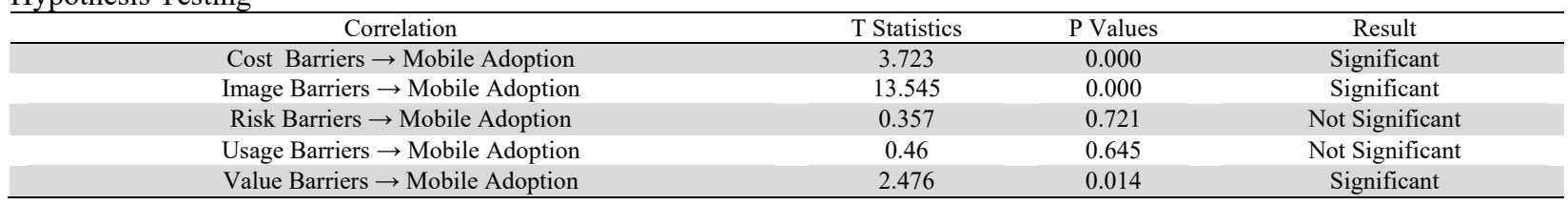

\section{Result}

\subsection{Effect of Risk Barriers on Adoption Intention}

Risk barriers have no significant effect on adoption intentions. This is because the risk barrier has a significant value of 0.721 which is more than 0.05 . This means that there is a positive but not significant effect between risk barriers and adoption intentions. This study is in line with the results of research conducted by Agwu et al. (2014) and Anus et al. (2011), which 
states that there is a positive relationship between risk barriers and adoption intentions. based on the results of research According to Ali and Kamran (2017), Albadvi and Gharaee (2009), stated that most respondents believe that it is still safe to use M-Banking services, but some respondents still do not agree because they feel that their personal information may fall into the wrong hands or data is lost when trying to use M-Banking services.

\subsection{Effect of Image Barriers on Adoption Intention}

Image barriers have a significant effect on adoption intentions. This is because the traditional barrier has a significant value of 0.000 which is less than 0.05 . This means that there is a negative influence between image barriers and adoption intentions. The results of this study are in line with the results of research conducted by According Brahim et al. (2015), Hanafizadeh et al. (2014), Hongxia et al. (2011) Image barriers are formed when consumers have had bad experiences and impressions in using digital services, According to Brahim et al. (2015), Hanafizadeh et al. (2014), Hongxia et al. (2011). Image barriers are formed when consumers have had bad experiences and impressions in using digital services before

\subsection{Effect of Cost Barriers Used on Adoption Intention}

The perceived cost barrier has a significant effect on adoption intentions. This is because the perceived cost barrier has a significant value of 0.000 which is less than 0.05 . This means that there is a positive influence between perceived cost barriers and adoption intentions. The fee to access the M-Banking service is fully charged to the user by deducting the credit balance. According to Khan et al. (2015), Govender et al. (2014), Iddris et al. (2013) The amount of the service fee depends on the service accessed by the user

\subsection{Effect of Usage barriers on Adoption Intention}

Barriers to use have no significant effect on adoption intentions. This is because the use barrier has a significant value of 0.645 which is more than 0.05 . This means that there is a positive influence between the barriers to use and the intention to adopt. According to Rahman (2013), According to Joshi et al. (2013), Laukkanen et al. (2008), Moorthy et al. (2017) the main reason for this barrier to occur is due to the level of user literacy which limits them in securing confidential information on the account when making transactions. The results of this study are not in accordance with the research conducted by Yee et al (2015) which states that there is a negative relationship between use barriers and adoption intentions. Millennials are considered more adaptive in the development of information technology so that usage barriers do not become dominant in the innovation adoption process.

\subsection{Effect of Value Barriers on Adoption Intention}

Value Barriers have a significant effect on adoption intentions. This is because the value barrier has a significant value of 0.014 which is less than 0.05 . This means that there is a significant influence between value barriers and adoption intentions. The results of this study are in line with the results of research conducted by millennials who feel that they do not have any advantages from M-Banking when compared to other ways they usually do, such as using bank teller services, ATMs, and physical money. Based on According Khan et al. (2015), Govender et al. (2014), Iddris et al. (2013). Another reason why value becomes a barrier is because users do not meet the desired experience such as comfort while using M-Banking.

In research conducted by According Brahim et al. (2015), Hanafizadeh et al. (2014), Hongxia et al. (2011) show a broader view of resistance by explaining the phenomenon through barriers that prevent or hinder acceptance with five barriers to acceptance (five barrier adoption). According to Brahim et al. (2015), Hanafizadeh et al. (2014), Hongxia et al. (2011) there are two main categories of causes of resistance, namely functional barriers and psychological barriers. According to Mei Ngan (2017), Okpara et al.. (2014), Sarokolaei et al. (2012), Siano et al. (2020) Functional barriers consist of use barriers, value barriers and risk barriers While psychological barriers consist of traditional barriers and image barriers Use barriers arise when an innovation does not match the workflow, practice or habits of users, because it takes more effort to learn and take advantage of innovation.

In the context of technology, barriers to use are related to complexity, which refers to the extent to which customers perceive to be able to understand and use a technology. According to Khan et al. (2015), Govender et al. (2014), Iddris et al. (2013) The more complicated or difficult a technology is, it will cause a reluctance to use the technology. When customers feel that mobile banking services are complicated to use, customers will switch to using other banking transactions. In mobile banking services, usage barriers are associated with the small size of the mobile device, including the small screen and keypad, making it difficult to use and hindering the use of mobile banking services. According to Khan et al. (2015), Govender et al. (2014), Iddris et al. (2013) A value barrier arises when a technology does not offer performance that matches the price, compared to another. Users feel that they do not benefit from using the technology, which is also called relative advantage. According to Mei Ngan (2017), Okpara et al. (2014), Sarokolaei et al. (2012), Siano et al. (2020) Relative advantage is influenced by perceived needs and costs. When customers feel the benefits of using mobile banking services are quite large, customers tend to accept mobile banking services even though the perceived needs are small. Meanwhile, when customers feel that mobile 
banking services are more expensive than other banking services, then customer resistance to mobile banking services will be high.

According to Khan et al. (2015), Govender et al. (2014), Iddris et al. (2013) Risk barriers are related to the level of risk perceived by customers. The greater the perceived risk, the less desire to use mobile banking services. In mobile banking services, the risk perceived by customers can be in the form of failed banking transactions because the smartphone suddenly turns off. In addition, smartphones are lost more often than computers or laptops. Thus causing concern to customers about the possibility of the loss of smartphones and bank accounts being misused by irresponsible people). According to Khan et al. (2015), Govender et al. (2014), Iddris et al. (2013) Tradition barriers occur when an innovation causes changes to the customer's traditions or daily routines. When the daily routine is considered important by customers, the barriers to tradition will be high. Some customers choose to make transactions by coming directly to the bank rather than using mobile banking services. Because customers feel social interaction is more important. Some customers also refuse to use mobile banking services because they are used to using ATMs. Image barriers come from one's perception of an innovation. When researching innovation resistance, images are used to estimate a product. According to Brahim et al. (2015), Hanafizadeh et al. (2014), Hongxia et al. (2011) Image barriers are positive or negative perceptions of a product, company, brand, country of origin, or difficulties in using new technology, which may be an obstacle to the acceptance of innovation in this case is mobile banking services. In the case of technological innovation, the picture barrier may stem from a negative view of the new technology.

\section{Conclusion}

Based on data analysis, we have concluded that there is a positive but not significant effect between risk barriers and mobile banking adoption intentions, there is a negative influence between image barriers and mobile banking adoption intentions. There is a positive influence between perceived cost barriers and mobile banking adoption intentions, there is a positive influence between the barriers to use and mobile banking adoption the intention to adopt. there is a significant influence between value barriers and mobile banking adoption intentions. Based on the results of the research and the conclusions that have been presented, the researcher then submits suggestions that may provide benefits to the parties involved in the results of this study. The suggestions that can be submitted are as follows: The obstacles felt by the millennial generation, can be suppressed, and minimized by the bank. If these obstacles can be suppressed, it is hoped that it will increase the intention to adopt M-Banking and can provide satisfaction for customers. The results of this study are expected to be a reference for further research by developing this research more broadly and in depth and using a wider research population.

\section{References}

Ali, A. A., \& Kamran, A. (2017). Barriers in Adopting M-Banking System in Universities. In Proceedings of the Tenth International Conference on Management Science and Engineering Management (pp. 191-202). Springer, Singapore.

Albadvi, A., \& Gharaee, R. (2009y). Drivers and Barriers of E-banking Adoption: Case of Karafarin Bank. In 2009 Third International Conference on Digital Society (pp. 235-240). IEEE.

Agwu, M. E., Atuma, O., Ikpefan, O. A., \& Iyoha, F. O. (2014). Adoption triggers and barriers of mobile banking services in Nigeria. International Review of Social Sciences, 2(9), 374-386.

Anus, S., Qureshi, F. A., Malik, S., Abbasi, A., Chaudhry, A., \& Mirza, S. N. (2011). Trust and initial acceptance of Mobile Banking in Pakistan. International Journal of Scientific \& Engineering Research, 2(8), 337-350.

Bao, X. R., Ling, S., \& Sun, M. G. (2012, October). Barriers and Solutions to the Development of the Mobile Banking in China. In Proceedings of the 2012 International Conference on Electronics, Communications and Control (pp. 22692272).

Bharti, M. (2016). Impact of dimensions of mobile banking on user satisfaction. Journal of Internet Banking and Commerce, 2l(1), 1.

Behl, A., \& Pal, A. (2016). Analysing the barriers towards sustainable financial inclusion using mobile banking in rural India. Indian Journal of Science and Technology, 9(15), 1-7.

Bamoriya, D., \& Singh, P. (2012). Mobile banking in India: Barriers in adoption and service preferences. Journal of Management, 5(1), 1-7.

Brahim, S. B., \& Dridi, M. (2015). Factors behind resisting mobile-banking adoption: The case of Tunisian consumers. International Journal of Sciences: Basic and Applied Research (IJSBAR), 24(1), 185-199.

Hanafizadeh, P., Behboudi, M., Koshksaray, A. A., \& Tabar, M. J. S. (2014). Mobile-banking adoption by Iranian bank clients. Telematics and informatics, 31(1), 62-78.

Hongxia, P., Xianhao, X. U., \& Weidan, L. I. U. (2011, May). Drivers and barriers in the acceptance of mobile payment in China. In 2011 International Conference on E-business and E-government (ICEE) (pp. 1-4). IEEE.

Khan, H., Talib, F., \& Faisal, M. N. (2015). An analysis of the barriers to the proliferation of M-Commerce in Qatar: A relationship modeling approach. Journal of Systems and Information Technology.

Govender, I., \& Sihlali, W. (2014). A study of mobile banking adoption among university students using an extended TAM. Mediterranean Journal of Social Sciences, 5(7), 451.

Iddris, F. (2013). Barriers to adoption of mobile banking: Evidence from Ghana. International Journal of Academic Research in Business and Social Sciences, 3(7), 356-370. 
Joshi, S. P., \& Salim, M. A. S. (2013). Analysis of barriers in Mobile Banking services which affects Consumer Utility and Bank Channel cost. IBMRD's Journal of Management \& Research, 2(1), 42-51.

Laukkanen, T., \& Cruz, P. (2008). Barriers to mobile banking adoption-A cross-national study. In International Conference on E-business (Vol. 2, pp. 300-306). SCITEPRESS.

Moorthy, K., Ling, C. S., Fatt, Y. W., Yee, C. M., Yin, E. C. K., Yee, K. S., \& Wei, L. K. (2017). Barriers of mobile commerce adoption intention: perceptions of generation $\mathrm{X}$ in Malaysia. Journal of theoretical and applied electronic commerce research, 12(2), 37-53.

Mei Ngan, W. (2017). Barriers to Customer Participation in Mobile Banking: In the Case of Hong Kong.

Munawaroh, M., Santoso B., Gumilang, R. R., Hidayatullah , D., Hermawan, A., Marhanah, S., ... \& Purwanto, A. (2021). The Effect of Strategic Leadership and Organization Culture on Business Performance: An Empirical Study in Indonesia. The Journal of Asian Finance, Economics and Business, 8(6), 455-463.

Okpara, A., Ailemen, I. O., \& Iyoha, F. O. (2014). Adoption Triggers and Barriers of Mobile Banking Services In Nigeria.

Pramono, R., Sondakh, L. W., Bernarto, I., Juliana, J., \& Purwanto, A. (2021). Determinants of the small and medium enterprises progress: A case study of SME entrepreneurs in Manado, Indonesia. The Journal of Asian Finance, Economics, and Business, $8(1), 881-889$.

Purwanto, A., Asbari, M., \& Santoso, T. (2021). Education Management Research Data Analysis: Comparison of Results between Lisrel, Tetrad, GSCA, Amos, SmartPLS, WarpPLS, and SPSS For Small Samples. Nidhomul Haq : Jurnal Manajemen Pendidikan Islam, 6(2), 382-399. https://doi.org/10.31538/ndh.v6i2.1575

Purba, N., Rosihan, R. P., Tanjung, A. M., Pramono, R., \& Purwanto, A. (2021). Efforts to Protect Violence in the Households during Covid-19 in Indonesia. International Journal of Criminology and Sociology, 10, 548-553.

Purwanto, A., Asbari, M., Santoso, T. I., Paramarta, V., \& Sunarsi, D. (2020). Social and Management Research Quantitative Analysis for Medium Sample: Comparing of Lisrel, Tetrad, GSCA, Amos, SmartPLS, WarpPLS, and SPSS. Jurnal Ilmiah Ilmu Administrasi Publik, 10(2), 518-532.

Purwanto, A., Asbari, M., Santoso, T. I., Sunarsi, D., \& Ilham, D. (2021). Education Research Quantitative Analysis for Little Respondents. Jurnal Studi Guru Dan Pembelajaran, 4(2), 335-350.

Sarokolaei, M. A., Rahimipoor, A., Nadimi, S., \& Taheri, M. (2012). The investigating of barriers of development of ebanking in Iran. Procedia-Social and Behavioral Sciences, 62, 1100-1106.

Siano, A., Raimi, L., Palazzo, M., \& Panait, M. C. (2020). Mobile Banking: An Innovative Solution for Increasing Financial Inclusion in Sub-Saharan African Countries: Evidence from Nigeria. Sustainability, 12(23), 10130.

Wanasida, A. S., Bernarto I., Sudibjo, N., \& Purwanto, A. (2021). The Role of Business Capabilities in Supporting Organization Agility and Performance During the COVID-19 Pandemic: An Empirical Study in Indonesia. The Journal of Asian Finance, Economics and Business, 8(5), 897-911.

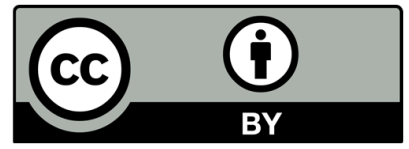

(C) 2021 by the authors; licensee Growing Science, Canada. This is an open access article distributed under the terms and conditions of the Creative Commons Attribution (CC-BY) license (http://creativecommons.org/licenses/by/4.0/). 